\title{
Opinion: Early COVID-19 testing in Peru and its implications on transmission
}

David J. Delgado-Diaz ${ }^{1 *}$, Maria Alejandra Zuniga-Gutierrez ${ }^{2}$, Charles A. Narh ${ }^{1,3,4}$, Jack S. Richards ${ }^{1,3,4}$

${ }^{1}$ ZIP Diagnostics Pty Ltd, Collingwood, VIC 3066, Australia

${ }^{2}$ Central Clinical School, Monash University, Clayton, VIC 3800, Australia.

${ }^{3}$ Burnet Institute for Medical Research, VIC 3004, Melbourne, Australia.

${ }^{4}$ Department of Medicine, University of Melbourne, VIC 3010, Melbourne, Australia

*Correspondence:

David Delgado-Diaz

david.d@zipdiag.com 


\begin{abstract}
As of September 8, 2021, severe acute respiratory syndrome coronavirus 2 (SARS-CoV-2) has infected more than 222 million and killed more than 4.3 million people. Peru is among the countries most affected by COVID-19, with more than 2.1 million cases and a fatality rate of 9.2\%. To limit SARS-CoV-2 spread into the country, Peru closed its borders to international travel in March 2020, and established strict lockdowns, while at the public health front, interventions including laboratory testing, contact tracing and isolation of suspected and/or infected individuals were largely inaccessible in communities with active transmission. Anecdotal reports suggest that a weak healthcare system and political instability contributed to the poor management of COVID-19 in the country. Here, we provide an opinion focused on the country's early testing response to the pandemic and discuss how it could have effectively leveraged diagnostic tools to control the spread of SARS-CoV-2.
\end{abstract}

Keywords: COVID-19, SARS-CoV-2, NAAT, RT-PCR, rapid antibody test, rapid antigen test. 


\section{Testing timeline and trends in Peru}

At the beginning of the pandemic, Peru lacked molecular diagnostic capability to mass screen communities at risk of SARS-CoV-2 transmission. This was not only due to the global shortages of testing supplies (1), but also due to the lack of decentralised molecular diagnostic laboratories (2) required to deal with the demand. Given these circumstances, its screening strategy was mainly based on triaging suspected cases using rapid serological tests $(3,4)$, which were cheap and easy to deploy across the country (2).

To further increase access to diagnosis, the government permitted private laboratories to offer testing to the public. However, the high cost associated with the latter was prohibitive for the poor, particularly, people living in overcrowded households and the lower socioeconomic classes, known to have the highest SARS-CoV-2 seroprevalence in Peru (5). Little was done to implement and sustain interventions including increasing access to free nucleic acid amplification tests (NAAT) and tracing of suspected COVID-19 cases and their contacts after the first wave of the pandemic $(3,6,7)$.

Data collected from The Peruvian Health Ministry COVID-19 website showed that the accumulated distribution of COVID-19 tests in Peru from the beginning of the pandemic to September 2021 was dominated by rapid antigen and rapid antibody tests, followed by PCR tests, accounting for $40.1 \%, 30.4 \%$, and $29.5 \%$, respectively (Figure $1 \mathrm{~A}$ ), with most of the infections being identified via rapid antibody tests (Figure 1B).

The test distribution data showed that rapid antigen tests were the most common test deployed in Peru to date. While rapid antibody tests were the predominant test from the start of the pandemic to November 2020 (Figure 1C), rapid antigen tests became the major test for COVID-19 diagnosis in January 2021 (Figure 1C). It is worth noting that although PCR 
capacity has increased since the beginning of the pandemic, rapid serological and rapid antigen tests have been the mainstay for COVID-19 testing in the country.

A considerable proportion of RT-PCR diagnostic testing (gold standard to detect infected individuals) for COVID-19 was centralised in two of the most populous Peruvian cities, the capital Lima and the province of Callao, while rapid serological tests (tests that indicate exposure but not necessarily active infection) were mainly used in other parts of the country (data available at https://covid19.minsa.gob.pe/sala_situacional.asp, https://www.dge.gob.pe/covid19.html) $(8,9)$. The large scale use of rapid antibody testing may have likely resulted in the under-reporting of active cases in the country, especially in provinces other than Lima and Callao, but was supported by the first Peruvian technical guidance for the management of the COVID-19 pandemic (10). This guidance was later updated and included RT-PCR and rapid antigen tests to detect SARS-CoV-2 infections.

The guidance for COVID-19 diagnosis (947-2020-MINSA), decreed in November 2020, recommended that individuals be tested for SARS-CoV-2 infection using antigen tests or RTPCR within the first seven days post-symptom onset, or via serological tests seven days or more post-symptom onset (11). While these timings coincide with viral RNA shedding dynamics and the appearance of antibody responses $(12,13)$, the guidance seemed to ignore pre-symptomatic and asymptomatic cases (close contacts, and other potential drivers of the transmission). These cohorts have been shown to significantly contribute to local SARS-CoV2 transmission $(14,15)$.

While rapid antigen tests in Peru may have been sufficient to confirm clinical cases, e.g., first 7 days post-symptom onset, they were less likely to detect pre-symptomatic and asymptomatic cases compared to RT-PCR tests $(16,17)$. Thus, it was likely that the total number of cases confirmed by antigen/antibody tests were underestimated since both tests are associated with 
high false-negative rates among pre-symptomatic and asymptomatic cases $(18,19)$. Although the technical guidance states that suspected cases with negative results should be retested after three to seven days of the first test, the reality was that most cases were usually not followed up.

\section{What does COVID-19 diagnosis based on serology mean?}

SARS-CoV-2 infected individuals typically develop an immune response approximately one to three weeks post-symptom onset, with the appearance of $\operatorname{IgM}$ antibodies followed by $\operatorname{IgG}$ antibodies (13). IgM antibodies disappear after a few weeks, while $\operatorname{IgG}$ antibodies circulate for months or years $(13,20)$. Therefore, an antibody test only tells us whether an individual was infected in the past, if the infection was recent, or if it occurred more than a few weeks ago. Nevertheless, an antibody test does not tell us whether the person has recovered and is not infectious anymore or whether the person is immune and protected against reinfection (21), and may not discriminate past infection from vaccination. Thus, antibody test results need to be interpreted cautiously in light of active infection; apart from that they are useful tools for seroprevalence studies.

\section{Discussion}

As RT-PCR test kits for COVID-19 were in limited supply during the early stage of the pandemic, Peru decided to utilise rapid antibody tests to triage suspected symptomatic cases and confirm the negative cases using RT-PCR (4). Although this triaging strategy aimed at relieving the testing backlogs and reducing waiting times associated with RT-PCR testing (4), the strategy was impractical, and COVID-19 diagnosis was based mostly on rapid antibody test results. Although it was not ideal, this strategy served as a quick public health response, but was unable to identify cases with active infections and stop the chain of transmission. 
After rapid antigen tests became available, the government improved its testing strategy by introducing them into its guidelines. Antigen tests are less sensitive than RT-PCR; however, they are less expensive and can be used to determine infectious individuals at the point-of-care (22). In this way, suspected cases and their contacts can be rapidly tested, isolated, and a RTPCR testing can be used to confirm active infection. Deploying antigen tests in territories, where RT-PCR is not available for confirmation, is not ideal unless testing resources and guidelines are in place to guarantee repeated antigen testing, which is known to increase the detection rate (23).

Strict lockdowns, border closures, and prolonged curfews require to be supplemented with extensive testing, contact tracing, and isolation of cases to be successful at controlling SARSCoV-2 transmission. Unfortunately, the early public health interventions rolled out by the Peruvian government (24) lacked these important considerations. The country, at that time did not count with decentralised molecular testing facilities and resources as well as an appropriate surveillance plan to implement testing, tracing, and isolation of COVID-19 cases.

Misdiagnosis of infections of those who were not seropositive at the time of testing has probably played a major role in sustaining local transmission(25). The high false-negative rates from the serological testing (25), undoubtedly underestimated the true infection rates, which may have given local authorities a false sense of security to relax control measures $(26,27)$.

The testing strategy implemented in Peru during the early stages of the pandemic seemed to have focused on detecting clinical cases rather than controlling transmission. It has been documented that the most infectious stage of the disease occurs prior to the body eliciting an adaptive immune response, both in symptomatic and asymptomatic individuals $(28,29)$. While mass testing in Peru would have been economically not feasible, making testing free and easily accessible to symptomatic cases and their close contacts could have been an effective way of 
controlling local outbreaks. Incentivising infected individuals by way of providing financial and job protection supports while in isolation may have also helped with compliance with quarantine and isolation rules (30).

\section{Conclusion}

Peru has been one of the countries hit hardest by the COVID-19 pandemic. Although SARSCoV-2 transmission in the country depended on several factors including a suboptimal testing strategy, the rate of transmission could have been mitigated by the usage of appropriate tools that facilitate the early detection and isolation of infected individuals and their close contacts. Due to the global shortage of PCR test kits, lack of facilities and decentralisation of molecular testing, Peru based its detection of COVID-19 cases on rapid antibody test results from April to December 2020. This approach may have underestimated the number of cases at the time of testing and facilitated the spread of the virus across the country. After December 2020, antigen tests have been the mainstay for the detection of SARS-CoV-2 infections; however, it is concerning that rapid antibody tests are still in use to detect infections. This experience highlights the importance of appropriate diagnostic preparedness to manage current and future emerging infectious diseases.

\section{References}

1. McMahon DE, Peters GA, Ivers LC, Freeman EE. Global resource shortages during COVID-19: bad news for low-income countries. PLoS neglected tropical diseases. 2020;14(7): 00008412.

2. Benítez MA, Velasco C, Sequeira AR, Henríquez J, Menezes FM, Paolucci F. Responses to COVID-19 in five Latin American countries. Health policy and technology. 2020;9(4):525-59.

3. Herrera-Añazco P, Uyen-Cateriano A, Mezones-Holguin E, Taype-Rondan A, MaytaTristan P, Malaga G, et al. Some lessons that Peru did not learn before the second wave of COVID-19. The International Journal of Health Planning and Management. 2021.

4. Peeling RW, Wedderburn CJ, Garcia PJ, Boeras D, Fongwen N, Nkengasong J, et al. Serology testing in the COVID-19 pandemic response. The Lancet Infectious Diseases. 2020.

5. Reyes-Vega MF, Soto-Cabezas MG, Cárdenas F, Martel KS, Valle A, Valverde J, et al. SARS-CoV-2 prevalence associated to low socioeconomic status and overcrowding in an 
LMIC megacity: A population-based seroepidemiological survey in Lima, Peru. EClinicalMedicine. 2021;34:100801.

6. Muñoz AV, Huamán HIM. Incremento del Coronavirus (COVID-19) en el Perú: por falta de responsabilidad social o bajo recursos económicos 2020. Hacedor-AIAPÆC. 2020;4(2):22-36.

7. Taylor L. Covid-19: Why Peru suffers from one of the highest excess death rates in the world. bmj. 2021;372.

8. OpenCovid-Peru. Sala Situacional COVID-19 en Peru 2021 [Available from: http://www.opencovid-peru.com/dashboard.

9. MINSA. Situacion del COVID-19 en el Peru 2021 [Archivo de la sala situacional del COVID-19 en el Peru]. Available from: https://www.dge.gob.pe/portalnuevo/covid-19/covidcajas/situacion-del-covid-19-en-el-peru/.

10. MINSA. Resolucion Ministerial 139-2020 MINSA. https://www.gob.pe/institucion/minsa/normas-legales/465962-139-2020-minsa2020.

11. MINSA. Resolución Ministerial 947-2020-MINSA. https://www.gob.pe/institucion/minsa/normas-legales/1359714-947-2020-minsa2020.

12. Lai CK, Lam W. Laboratory testing for the diagnosis of COVID-19. Biochemical and biophysical research communications. 2021;538:226-30.

13. Fu Y, Li Y, Guo E, He L, Liu J, Yang B, et al. Dynamics and correlation among viral positivity, seroconversion, and disease severity in COVID-19: a retrospective study. Annals of Internal Medicine. 2021;174(4):453-61.

14. Subramanian R, He Q, Pascual M. Quantifying asymptomatic infection and transmission of COVID-19 in New York City using observed cases, serology, and testing capacity. Proceedings of the National Academy of Sciences. 2021;118(9).

15. Moghadas SM, Fitzpatrick MC, Sah P, Pandey A, Shoukat A, Singer BH, et al. The implications of silent transmission for the control of COVID-19 outbreaks. Proceedings of the National Academy of Sciences. 2020;117(30):17513-5.

16. Toptan T, Eckermann L, Pfeiffer AE, Hoehl S, Ciesek S, Drosten C, et al. Evaluation of a SARS-CoV-2 rapid antigen test: Potential to help reduce community spread? Journal of Clinical Virology. 2021;135:104713.

17. Mina MJ, Peto TE, García-Fiñana M, Semple MG, Buchan IE. Clarifying the evidence on SARS-CoV-2 antigen rapid tests in public health responses to COVID-19. The Lancet. 2021;397(10283):1425-7.

18. Linares M, Pérez-Tanoira R, Carrero A, Romanyk J, Pérez-García F, Gómez-Herruz P, et al. Panbio antigen rapid test is reliable to diagnose SARS-CoV-2 infection in the first 7 days after the onset of symptoms. Journal of Clinical Virology. 2020;133:104659.

19. Torres I, Poujois S, Albert E, Colomina J, Navarro D. Evaluation of a rapid antigen test (Panbio ${ }^{\mathrm{TM}}$ COVID-19 Ag rapid test device) for SARS-CoV-2 detection in asymptomatic close contacts of COVID-19 patients. Clinical Microbiology and Infection. 2021;27(4):636. e1-. e4. 20. Glück V, Grobecker S, Tydykov L, Salzberger B, Glück T, Weidlich T, et al. SARS$\mathrm{CoV}$-2-directed antibodies persist for more than six months in a cohort with mild to moderate COVID-19. Infection. 2021:1-8.

21. Iwasaki A. What reinfections mean for COVID-19. The Lancet Infectious Diseases. 2021;21(1):3-5.

22. Korenkov M, Poopalasingam N, Madler M, Vanshylla K, Eggeling R, Wirtz M, et al. Evaluation of a rapid antigen test to detect SARS-CoV-2 infection and identify potentially infectious individuals. Journal of clinical microbiology. 2021;59(9):e00896-21.

23. Larremore DB, Wilder B, Lester E, Shehata S, Burke JM, Hay JA, et al. Test sensitivity is secondary to frequency and turnaround time for COVID-19 screening. Science Advances. 2021;7(1):eabd5393. 
24. Alvarado K, Alvarado S, Esenarro D, Rodríguez C, Iannacone J, Alvariño L, et al. Estrategia nacional peruana contra la propagación de la pandemia del coronavirus (COVID19). Cátedra Villarreal. 2020;8(1).

25. Cassaniti I, Novazzi F, Giardina F, Salinaro F, Sachs M, Perlini S, et al. Performance of VivaDiag COVID-19 IgM/IgG Rapid Test is inadequate for diagnosis of COVID-19 in acute patients referring to emergency room department. Journal of medical virology. 2020.

26. West CP, Montori VM, Sampathkumar P, editors. COVID-19 testing: the threat of false-negative results. Mayo Clinic Proceedings; 2020: Elsevier.

27. Mahase E. Covid-19: People are not being warned about pitfalls of mass testing. British Medical Journal Publishing Group; 2021.

28. van Kampen JJ, van de Vijver DA, Fraaij PL, Haagmans BL, Lamers MM, Okba N, et al. Duration and key determinants of infectious virus shedding in hospitalized patients with coronavirus disease-2019 (COVID-19). Nature communications. 2021;12(1):1-6.

29. Sayampanathan AA, Heng CS, Pin PH, Pang J, Leong TY, Lee VJ. Infectivity of asymptomatic versus symptomatic COVID-19. The Lancet. 2021;397(10269):93-4.

30. Wright AL, Sonin K, Driscoll J, Wilson J. Poverty and economic dislocation reduce compliance with covid-19 shelter-in-place protocols. Journal of Economic Behavior \& Organization. 2020;180:544-54. 
A

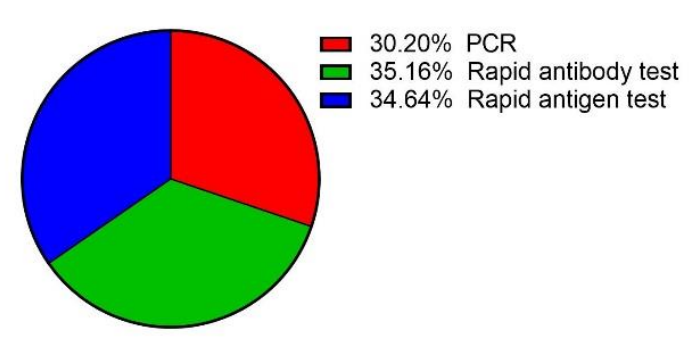

Total $=14,437,212$ tests done

C

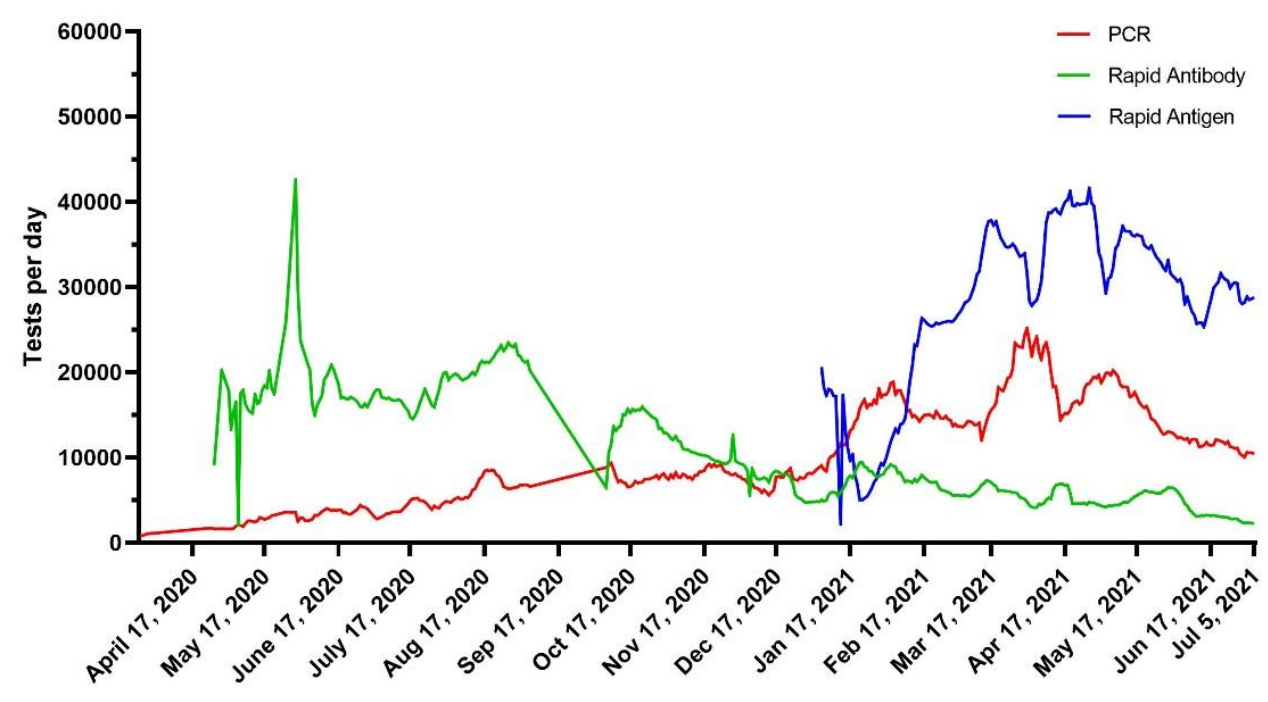

Figure 1. Total and daily distribution of COVID-19 test types and total positivity rates in

Peru. Total number of PCR, rapid antibody tests, and antigen tests performed (A), and their positivity (B) was obtained from the Peruvian Health Ministry COVID-19 website and includes data from March 05, 2020, to September 06, 2021. Daily distribution of COVID-19 tests is depicted as a rolling 7-day average and included data from April 2020 to September 2021. Raw data was collected from The Peruvian Health Ministry COVID-19 website and OpenCovidPeru.com. 